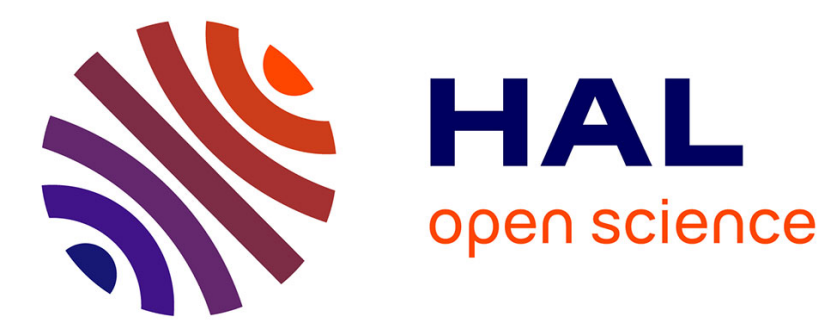

\title{
Legionella: from protozoa to humans
}

Carmen Buchrieser

\section{To cite this version:}

Carmen Buchrieser. Legionella: from protozoa to humans. Frontiers in Microbiology, 2011, 2, pp.182. 10.3389/fmicb.2011.00182 . pasteur-01422821

HAL Id: pasteur-01422821

https://hal-pasteur.archives-ouvertes.fr/pasteur-01422821

Submitted on 27 Dec 2016

HAL is a multi-disciplinary open access archive for the deposit and dissemination of scientific research documents, whether they are published or not. The documents may come from teaching and research institutions in France or abroad, or from public or private research centers
L'archive ouverte pluridisciplinaire HAL, est destinée au dépôt et à la diffusion de documents scientifiques de niveau recherche, publiés ou non, émanant des établissements d'enseignement et de recherche français ou étrangers, des laboratoires publics ou privés.

\section{(c)(1)}

Distributed under a Creative Commons Attribution| 4.0 International License 


\section{Legionella: from protozoa to humans}

\section{Carmen Buchrieser*}

Institut Pasteur, Biologie des Bactéries Intracellulaires and CNRS URA 2171, Paris, France

${ }^{*}$ Correspondence: cbuch@pasteur.fr
Pathogens that are able to enter and multiply within human cells are responsible for multiple diseases and millions of deaths worldwide. Thus, the challenge is to elucidate these pathogen-specific and cell biological mechanisms involved in intracellular growth and spread. Bacteria from the genus Legionella belong to this group of pathogens. They are environmental bacteria and ubiquitous in nature, where they parasitize protozoa. Strikingly, the capacity to grow intracellularly in protozoa like Acanthamoeba castellanii, Hartmannella sp., or Naegleria sp., has generated a pool of virulence traits during evolution, which allow Legionella to infect also human cells. Thus important human pathogens are present within the genus Legionella, the most prominent are L. pneumophila (Fraser et al., 1977; Mcdade et al., 1977) and L. longbeachae (Mckinney et al., 1981). These bacteria are the causative agents of Legionnaires' disease, a severe pneumonia diagnosed mainly in people whose immune defenses are weakened. Legionella is transmitted through breathing infected aerosols present in many artificial water systems like air conditioning systems, cooling towers, showers, and other aerosolizing devices. When reaching the alveolar parts of the lungs Legionella is engulfed by macrophages where it is able to multiply resulting in a severe, often fatal pneumonia. Intracellular infection is a consequence of the bacterium's capacity to manipulate host cellular processes using bacterial proteins that are delivered into the host cell by specialized secretion systems (Isberg et al., 2009; Hubber and Roy, 2010). In this Research Topic, we present a collection of Review, Opinion, Perspective, and Primary research articles that present both the well-established and the newly discovered strategies used by Legionella to achieve this intracellular lifestyle while escaping from the host immune response.

Recent advance in genome sequencing has had a tremendous impact on our understanding of the pathogenesis, evolution and diversity of L. pneumophila and L. long- beachae and the knowledge of the genome sequence has guided and facilitated the research on Legionella in many laboratories. Starting this issue, Gomez Valero et al. (2011) present a comprehensive review on what we have learned from the sequencing and analyses of six L. pneumophila and five L. longbeachae genomes published since 2004. In particular, genome sequence analysis revealed the presence of proteins with high similarity to eukaryotic proteins or proteins with domains preferentially or only present in eukaryotic genomes that are mimicking host functions helping the pathogen to replicate intracellularly (Cazalet et al., 2004, 2010). Further insight in the genetic basis of host differences and the evolution of the eukaryotic like proteins in these two pathogens are given.

The bacterial cell wall is at the forefront of the interaction with the host and is essential for cellular integrity and the resistance to external stress and aggressions. Shevchuk et al. (2011) provide an update on the structure, molecular composition, and virulence properties of the L. pneumophila cell envelope. In their review they show convincingly that lipopolysaccharide and several outer membrane proteins like Mip, a peptidylprolyl-cis/trans isomerase, a phospholipase A are essential virulence factors. It becomes clear that promising new fields of research will be the analyses of proteins, carbohydrates, and lipids of the cell envelope as they serve for both, structural and signaling roles. In the following review article Garduno et al. (2011) present us the current knowledge on the many functions that one of these outer membrane proteins, Hsp60 or HtpB plays in the L. pneumophila biology. This chaperonin is an unusual multifunctional protein which was discovered already as early as 1986 as an antigen that prominently reacted with patients diagnosed with Legionnaires' disease. Over 20 years later it has been shown to have protein folding as well as protein folding independent roles and that it is associated with virulence and survival of L. pneumophila.
Central to the pathogenesis of L. pneumophila and L. longbeachae is its Type IV secretion system (T4SS) called Dot/Icm. It is predicted to translocate over 270 effector proteins into the host cell which allow this bacterium to manipulate host cell functions to its advantage and to assure intracellular survival and replication. Nagai and Kubori (2011) recapitulate our present understanding of the T4SS apparatus and its components by taking advantage of genomic and structural information. Finally, using comparative genomics information of several bacteria and plasmids carrying similar systems a comparative analysis of T4SS components is presented. The following five reviews, research, and opinion articles discuss some of the secreted effectors of this T4SS and their divers roles in pathogenesis of L. pneumophila. Hilbi et al. (2011) present evidence that $L$. pneumophila subverts phosphoinositide (PI) lipids by anchoring specific effectors through distinct PIs to the cytosolic face of the Legionella containing vacuole (LCV) to promote the interaction with host vesicles and organelles, catalyze guanine nucleotide exchange of small GTPases, or bind to PI-metabolizing enzymes. Interestingly, $L$. pneumophila secretes also three glycosyltransferases through its T4SS. Belyi et al. (2011) report on this novel family of effector proteins that are structurally similar to clostridial glycosylating toxins. However, in L. pneumophila they do not produce toxic effects but modify the eukaryotic elongation factor EF1A to inhibit protein synthesis and subsequently to induce cell death. Another exciting strategy employed by L. pneumophila by secreting proteins encoding a eukaryotic F-box domain is the exploitation of the host's polyubiquitination and farnesylation machineries. In an original research article Al-Quadan and Kwaik (2011) discuss in detail how one of the L. pneumophila encoded F-box proteins uses these conserved eukaryotic signaling pathways to proliferate in Dictyostelium discoideum, a model ameba used as infection 
model. Excitingly, this same effector also has another eukaryotic motif, which is used by the host's prenylation machinery for anchoring it in the outer leaflet of the LCV (Ivanov et al., 2010; Price et al., 2010). In another primary research article Price et al. (2010) show, that L. pneumophila contain several other proteins with this motif, that are also used by the host prenylation machinery to anchor proteins into cellular membranes contributing in this way to the evasion of lysosomal fusion by the LCV.

A further strategy of L. pneumophila to establish an environment beneficial to replication is to specifically targets and exploit the host phosphorylation system through T4SS effectors that act directly on phosphorylation cascades. Haenssler and Isberg (2011) present a comprehensive and exciting review on the different host kinases and phosphatases that are targeted during L. pneumophila infection and show how L. pneumophila modulates host cell signal transduction by phosphorylation at multiple levels. The part discussing the different strategies of L. pneumophila to modulate host functions through T4SS effectors of L. pneumophila finishes with an opinion article by Luo (2011b) that discusses a recent, stimulating finding. L. pneumophila has evolved an effector protein, which specifically target another bacterial effector protein for degradation to shutdown its action within the host cells at later stages of infection. This demonstrates a sophisticated level of coevolution between eukaryotic cells and L. pneumophila involving an effector that functions as a key regulator to temporally coordinate the function of a cognate effector protein and opens now the way for additional research into possible interaction of bacterial effectors among them and not only with host proteins.

To timely secret this large repertoire of different effectors and to adapt the metabolism and the physiology of L. pneumophila to the changing host environment, a tight regulation of the expression of the different genes coding these proteins is necessary. Thus L. pneumophila has evolved a complex regulatory system and many different regulatory elements governing its life cycle. One of the master regulators is CsrA that is regulated by binding to two small regulatory RNAs (Rasis and Segal, 2009; Sahr et al., 2009). Faucher and Shuman (2011) give an overview of what is known about small regulatory RNAs in L. pneumophila and present in a second article the first transcriptome analysis of L. pneumophila infecting human macrophages (Faucher et al., 2011). A model of the regulatory networks involving small RNA mediated control of virulence gene regulation in L. pneumophila is presented.

In the following part of this Research Topic Joshi and Swanson stress important aspects of Legionella-host interactions, by providing a critical view on the Legionella response to autophagy, a host defense against invading microbes (Joshi and Swanson, 2011). They propose that L. pneumophila is able to halt the autophagosome maturation by secreting different effector proteins. Once L. pneumophila adapted to an acidic environment another effector, LepB releases this blockage and the now acid resistant $L$. pneumophila are able to continue replicating in these autophagolysosomes. In the following article, Luo discusses recent progress in understanding the mechanisms L. pneumophila employs to interfere with apoptosis and how this modulation also contributes to the intracellular life cycle of this bacterium (Luo, 2011a).

Finally, infection by a pathogen and its outcome is always an interplay between the pathogen and the host. Thus, the host response to infection with $L$. pneumophila is a very important research question. This topic is the focus of a review by Massis and Zamboni (2011) that summarizes the current knowledge of the innate immune response to L. pneumophila infection. The implication of the different families of pattern recognition receptors (PRR) like TLRs, NLRs, and RLRs are discussed and a comprehensive analyses of the events triggered by the recognition of intracellular $L$ pneumophila by these PRRs is presented. Schuelein et al. (2011) close this research topic by providing a thoughtful opinion article about the immune control of Legionella infection. The authors stress that macrophages play a pivotal role in initiating the host response to L. pneumophila infection, however, given the fact that the resolution of L. pneumophila infection needs multiple cell types and abundant cross talk between immune cells they propose that the role of other cell types such as dendritic cells and the mechanism of action of protective cytokines should be examined in the future.
The field of microbiology and the study of host pathogen interactions is moving fast ahead and, in conjunction with the avalanche of data provided by the application of new, powerful "omics" methods, the tremendous advances in imaging techniques allowing in vivo, and single cell analyses and improvements in analytical methods, will lead to many exciting new discoveries in the future.

\section{REFERENCES}

Al-Quadan, T., and Kwaik, Y. A. (2011). Molecular characterization of exploitation of the polyubiquitination and farnesylation machineries of Dictyostelium discoideum by the ankb f-box effector of Legionella pneumophila. Front. Microbiol. 2:23. doi: 10.3389/ fmicb.2011.00023

Belyi, Y., Jank, T., and Aktories, K. (2011). Effector glycosyltransferases in Legionella. Front. Microbiol. 2:76. doi: $10.3389 /$ fmicb. 2011.00076

Cazalet, C., Gomez-Valero, L., Rusniok, C., Lomma, M., Dervins-Ravault, D., Newton, H. J., Sansom, F. M., Jarraud, S., Zidane, N., Ma, L., Bouchier, C., Etienne, J., Hartland, E. L., and Buchrieser, C. (2010). Analysis of the Legionella longbeachae genome and transcriptome uncovers unique strategies to cause Legionnaires' disease. PLoS Genet. 6, e1000851. doi: 10.1371/journal. pgen. 1000851

Cazalet, C., Rusniok, C., Bruggemann, H., Zidane, N., Magnier, A., Ma, L., Tichit, M., Jarraud, S., Bouchier, C., Vandenesch, F., Kunst, F., Etienne, J., Glaser, P., and Buchrieser, C. (2004). Evidence in the Legionella pneumophila genome for exploitation of host cell functions and high genome plasticity. Nat. Genet. 36, 1165-1173.

Faucher, S. P., Mueller, C. A., and Shuman, H. A. (2011). Legionella pneumophila transcriptome during intracellular multiplication in human macrophages. Front. Microbiol. 2:60. doi: 10.3389/fmicb.2011.00060

Faucher, S. P., and Shuman, H.A. (2011). Small regulatory RNA and Legionella pneumophila. Front. Microbiol. 2:98. doi: 10.3389/fmicb.2011.00098

Fraser, D. W., Tsai, T. R., Orenstein, W., Parkin, W. E., Beecham, H. J., Sharrar, R. G., Harris, J., Mallison, G. F., Martin, S. M., Mcdade, J. E., Shepard, C. C., and Brachman, P.S. (1977). Legionnaires' disease: description of an epidemic of pneumonia. N. Engl. J. Med. 297, 1189-1197.

Garduno, R. A., Chong, A., Nasrallah, G. K., and Allan, D. S. (2011). The Legionella pneumophila chaperonin - an unusual multifunctional protein in unusual locations. Front. Microbiol. 2:122. doi: 10.3389/ fmicb.2011.00122

Gomez Valero, L., Runsiok, C., Cazalet, C., and Buchrieser, C. (2011). Comparative and functional genomics of Legionella identified eukaryotic like proteins as key players in host-pathogen interactions. Front. Microbiol. 2:208. doi: 10.3389/fmicb.2011.00208

Haenssler, E., and Isberg, R. R. (2011). Control of host cell phosphorylation by Legionella pneumophila. Front. Microbiol. 2:64. doi: 10.3389/ fmicb.2011.00064

Hilbi, H., Weber, S., and Finsel, I. (2011). Anchors for effectors: subversion of phosphoinositide lipids by Legionella. Front. Microbiol. 2:91. doi: 10.3389/ fmicb.2011.00091 
Hubber, A., and Roy, C. R. (2010). Modulation of host cell function by Legionella pneumophila type IV effectors. Annu. Rev. Cell Dev. Biol. 26, 261-283.

Isberg, R. R., O'connor, T. J., and Heidtman, M. (2009). The Legionella pneumophila replication vacuole: making a cosy niche inside host cells. Nat. Rev. Microbiol. 7, 13-24.

Ivanov, S. S., Charron, G., Hang, H. C., and Roy, C. R. (2010). Lipidation by the host prenyltransferase machinery facilitates membrane localization of Legionella pneumophila effector proteins. J. Biol. Chem. 285, 34686-34698.

Joshi, A. D., and Swanson, M. S. (2011). Secrets of a successful pathogen: Legionella resistance to progression along the autophagic pathway. Front. Microbiol. 2:138. doi: 10.3389/fmicb. 2011.00138

Luo, Z. Q. (2011a). Striking a balance: modulation of host cell death pathways by Legionella pneumophila. Front. Microbiol. 2:36. doi: 10.3389/fmicb.2011.00036

Luo, Z. Q. (2011b). Targeting one of its own: expanding roles of substrates of the Legionella pneumophila Dot/ Icm type iv secretion system. Front. Microbiol. 2:31. doi: $10.3389 /$ fmicb. 2011.00031

Massis, L. M., and Zamboni, D. S. (2011). Innate immunity to Legionella pneumophila.Front. Microbio. 2:109. doi: 10.3389/fmicb.2011.00109

Mcdade, J. E., Shepard, C. C., Fraser, D. W., Tsai, T. R., Redus, M.A., and Dowdle, W. R. (1977). Legionnaires' disease: isolation of a bacterium and demonstration of its role in other respiratory disease. N. Engl. J. Med. 297, 1197-1203.

Mckinney, R. M., Porschen, R. K., Edelstein, P. H., Bissett, M. L., Harris, P. P., Bondell, S. P., Steigerwalt, A. G., Weaver, R. E., Ein, M. E., Lindquist, D. S., Kops, R. S., and Brenner, D. J. (1981). Legionella longbeachae species nova, another etiologic agent of human pneumonia. Ann. Intern. Med. 94, 739-743.

Nagai, H., and Kubori, T. (2011). Type IVB secretion systems of Legionella and other Gram-negative bacteria. Front. Microbiol. 2:136. doi: 10.3389/ fmicb.2011.00136

Price, C. T., Al-Quadan, T., Santic, M., Jones, S. C., and Abu Kwaik, Y. (2010). Exploitation of conserved eukaryotic host cell farnesylation machinery by an F-box effector of Legionella pneumophila. J. Exp. Med. 207, 1713-1726.

Price, C. T., Jones, S. C., Amundson, K. E., and Kwaik, Y.A. (2010). Host-mediated post-translational prenylation of novel dot/icm-translocated effectors of Legionella pneumophila. Front. Microbiol. 1:131. doi: 10.3389/ fmicb.2010.00131

Rasis, M., and Segal, G. (2009). The LetA-RsmYZ-CsrA regulatory cascade, together with RpoS and PmrA, post-transcriptionally regulates stationary phase activation of Legionella pneumophila Icm/Dot effectors. Mol. Microbiol. 72, 995-1010.
Sahr, T., Bruggemann, H., Jules, M., Lomma, M., AlbertWeissenberger, C., Cazalet, C., and Buchrieser, C. (2009). Two small ncRNAs jointly govern virulence and transmission in Legionella pneumophila. Mol. Microbiol. 72, 741-762.

Schuelein, R., Ang, D. K., Van Driel, I. R., and Hartland, E. L. (2011). Immune control of Legionella infection: an in vivo perspective. Front. Microbiol. 2:126. doi: 10.3389/fmicb.2011.00126

Shevchuk, O., Jäger, J., and Steinert, M. (2011). Virulence properties of the Legionella pneumophila cell envelope. Front. Microbiol. 2:74. doi: 10.3389/ fmicb.2011.00074

Received: 15 August 2011; accepted: 18 August 2011; published online: 12 October 2011.

Citation: Buchrieser, C (2011) Legionella: from protozoa to humans. Front. Microbio. 2:182. doi: 10.3389/ fmicb.2011.00182

This article was submitted to Frontiers in Cellular and Infection Microbiology, a specialty of Frontiers in Microbiology.

Copyright (C) 2011 Buchrieser. This is an open-access article subject to a non-exclusive license between the authors and Frontiers Media SA, which permits use, distribution and reproduction in other forums, provided the original authors and source are credited and other Frontiers conditions are complied with. 